\title{
POPULATION'S SOCIAL SENTIMENT AND RISKS OF FALLING LIVING STANDARDS ${ }^{1}$ \\ E.Avraamova, D.Loginov
}

Findings of survey report released by the Institute of Social Analysis and Forecasting (RANEPA) demonstrate a reduced dramatics of the economic situation in the country and reduced duration of the crisis. However, negative expectations are still strong first of all in the sphere of employment. Consumption activity still remains depressed.

The latest survey (September 2016) has demonstrated a significant growth of positive assessments of shifts taken place in the economic situation of the country (Table 1). Nearly half of respondents indicate stabilization of economic situation - this is the all-time maximum registered from the probe's onset (since February 2015).

Table 1

\section{ESTIMATES OF CHANGES IN THE ECONOMIC SITUATION OF THE COUNTRY} (TOTAL)

\begin{tabular}{|l|c|c|c|c|}
\hline \multirow{2}{*}{ Nature of changes } & \multicolumn{4}{|c}{$\%$ of answers of the number of respondents } \\
\cline { 2 - 5 } & Feb 2015 & Sep 2015 & June 2016 & Sep 2016 \\
\hline Improved & 2.7 & 3.6 & 4.6 & 7.4 \\
\hline Not improved & 17.3 & 38.4 & 38.0 & 45.7 \\
\hline Deteriorated negligibly & 32.6 & 27.4 & 22.8 & 20.1 \\
\hline Deteriorated noticeably & 37.1 & 21.2 & 24.6 & 17.3 \\
\hline $\begin{array}{l}\text { Ongoing full- } \\
\text { fledged crisis }\end{array}$ & 7.9 & 5.0 & 6.6 & 5.8 \\
\hline No answer & 2.4 & 4.4 & 3.6 & 3.7 \\
\hline
\end{tabular}

Moreover, the share of those believing that it will take one or two years more to the country to exit from the crisis diminished, while the number of those who hope that this can happen sooner increased (Fig. 1).

General and overall positive assessments of prospects of weathering the crisis do not correspond with information about the extent the citizens suffer from it. Positive shifts are revealed in the fact that the share of population affected by the crisis has diminished to a great

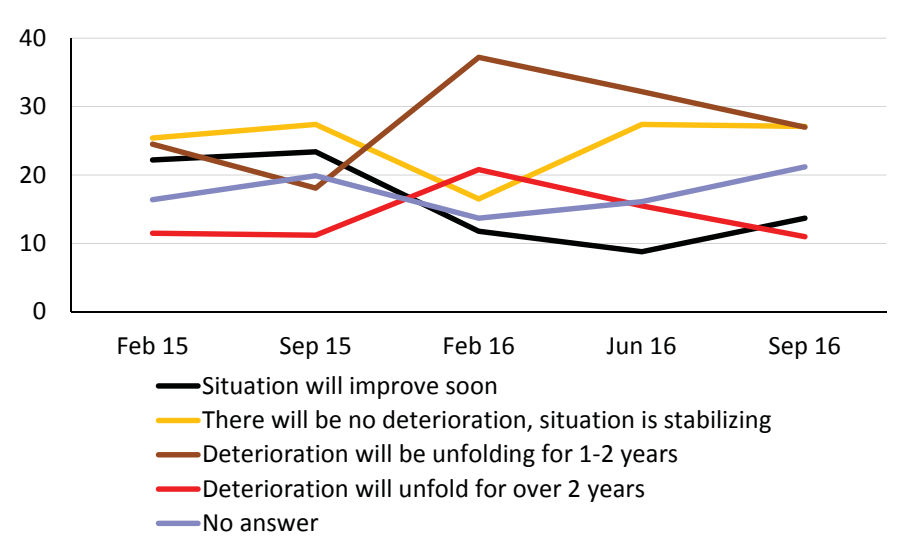

Fig. 1. Assessment of duration of negative effects in economy, $\%$ of answers of the number of respondents extent. The number of those who are slightly affected (45\%) and of those who are still unaffected but are afraid of it in the future (16\%) has somewhat increased.

1 This paper was originally published in Online Monitoring of Russia's Economic Outlook No.17(35). 
At the same time, in comparison with the previous probe (June 2016), assessment of the situation in employment has somewhat gone for the worse: a share of those who feel threatened of a job loss has increased by $5 \%$; $31 \%$ of respondents remain in the zone of this risk perseption.

$40 \%$ of jobholders noted that over the last month, the state of their enterprises has gone for the worse and $22 \%$ think that it will be even

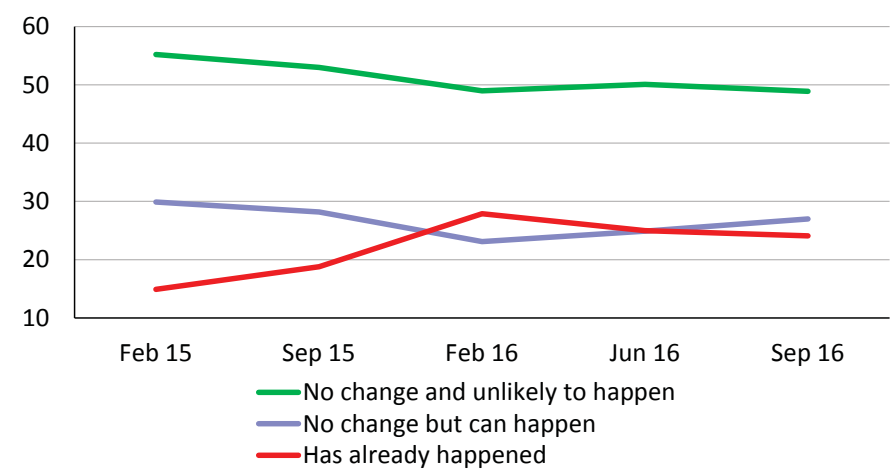

Fig. 2. Assessment of adjustment of wage rates, \% respondent choosing one or another answer of the number of respondents worse in the months to come. High professional stance does not warrant stable employment, although the highest risk of job loss has been observed among the less qualified employees. $10.5 \%$ of the respondents are in two minds about a chance to retain a job and think that the prospects of further employment are uncertain.

Assessment of adjustment of wage rates has somewhat shifted to the negative in comparison with the previous probe: approximately by $2 \%$ contracted the number of those who were not affected by a wage rate reduction and unlikely to be affected. To the same degree has gone up the share of those who is afraid of wage rate drop.

At the same time, the level of negative expectations regarding employment does not go down. To compare last year's expectations regarding certain events (job loss, going on leave without pay, part-time working week, pay pause and wage reduction) and actual occurrence of such events, one can come to the following conclusions:

- concerns of those who expected wage rate adjustment have been amply demonstrated and the level of negative expectations regarding this event has remained at the same level;

- concerns related to the pay pause have been confirmed;

- concerns regarding job loss have been confirmed by more than half of those who expressed them a year earlier and the volume of negative expectations of this prospect remained at the same level; in other words, part of the population views the prospect of a job loss as a suspended prospect.

The place of residence is the key factor, which determines maximum likelihood of risks in employment. The residents of a metropolis face maximum risks possibly owing to the fact that their employment to a greater extent goes beyond a relatively more stable budgetary sphere.

Stick out those types of activity, which differentiate by the likelihood of risks. Among the least risky are first of all public administration and law enforcement agencies (over $60 \%$ of employed in these spheres do not feel risks). Those employed in industry, construction, transport, and communications express the highest concerns.

The September survey has demonstrated a lack of consumer activity neither on the whole nor on certain types of goods and services. Consumption contraction continues to be passive but it is the most widespread form of adaptation, which Russian low and middle walks of life practice. On the whole, the population takes changes rather quietly owing to savings during 
the fat years, which permits to reduce spending on purchasing durable goods without negatively affecting the quality of life.

Possessions can be nominally divided into household goods, gadgets and luxury goods, which determine higher quality of life. Table 2 demonstrates that representatives of all walks of life equally boast of household goods (TV, fridge, and washing machine). In this respect a $100 \%$ saturation has been accomplished. Gadgets (mobile phones, smartphones, computers, etc.) are also widely owned and one can speak about the introduction of gadgets among needful goods. At the same time, the number of owners of corresponding goods is noticeably shifting towards upper stratified groups especially towards core of the middle class who nearly all own them. Regarding luxury goods (dishwashers, and air conditioners), they largely are owned by representative of the core of the middle class ${ }^{1}$.

Table 2

POSSESSIONS OF STRATIFIED GROUP REPRESENTATIVES, \%

\begin{tabular}{l|c|c|c|}
\hline \multirow{2}{*}{} & \multicolumn{3}{|c|}{ Level of property in possession } \\
\cline { 2 - 4 } & $\begin{array}{c}\text { Having fridge / } \\
\text { washing machine }\end{array}$ & $\begin{array}{c}\text { Having dishwasher } \\
\text { / air conditioner }\end{array}$ & $\begin{array}{c}\text { Having PC / smart } \\
\text { phone / internet }\end{array}$ \\
\hline $\begin{array}{l}\text { Low walk } \\
\text { of life }\end{array}$ & 98.1 & 10.5 & 80.9 \\
\hline $\begin{array}{l}\text { Far periphery } \\
\text { Close } \\
\text { periphery }\end{array}$ & 98.9 & 17.4 & 90.5 \\
\hline Core & 99.5 & 25.5 & 91.7 \\
\hline Total & 98.5 & 39.0 & 96.6 \\
\hline
\end{tabular}

The middle class core stands out as the most comfortably off people, although $30 \%$ of them need renovation of possessions and solely half of them are financially able to implement it. Options of walks of like beyond this core are far less. Contraction of the consumer activity currently can be viewed as a rather compressed in time adaptability strategy. In the long run this strategy will miss the mark and one can project collision not between a "fridge and a TV set" (food products, albeit with a reduced quality will be accessible to all segments of the people) and between TV set and, for example, a smartphone.

Besides economy on spending, work of a subsidiary plot of land is getting an even greater expansion as adaptability strategy. Adaptation behavior in the sphere of employment on the contrary is depressed.

1 In case of matching criteria pertinent to the middle class (social and professional status, level of material well-being, and self-identity) there is a core of the middle class, which constitutes $18.5 \%$ of respondents; two criteria - 'close periphery' - $30.2 \%$; one criterion - 'far periphery' $-25.5 \%$ of respondents. 